\title{
Change in estrogenic activity in stored human urine before reuse as fertilizer
}

\author{
Maria Alejandra Arias ${ }^{1}\left[\right.$ ] Ute Arnold ${ }^{1} \cdot$ Heiner Goldbach ${ }^{1}$
}

Received: 20 August 2018 / Accepted: 13 July 2019 / Published online: 18 July 2019

(c) The Author(s) 2019

\begin{abstract}
Purpose Recycling of nutrients from human excreta may offer an opportunity for smallholder farms to improve crop nutrition and soil fertility. However, when applying human urine as fertilizer, it may load natural and synthetic estrogens into the environment. To avoid pollution by endocrine disruptors, treatment methods before field application must be implemented. The present study thus aims to evaluate the reduction in estrogenic activity in human urine during the storage period before urine is applied to the field.

Methods This study evaluated the estrogenic activity in diluted urine (DU) exposed to simulated sunlight (280-700 nm) and under dark conditions for 75 days. Estrogenic activity was analyzed using the recombinant yeast estrogen screen assay. Concentrations of total nitrogen $\left(N_{\text {tot }}\right)$, ammonium- $\mathrm{N}\left(\mathrm{NH}_{4}-\mathrm{N}\right)$ and dissolved organic carbon were measured, as well as electrical conductivity and $\mathrm{pH}$. Correlation of factors to the reduction of the estrogenic activity was also evaluated.

Results Decay of estrogenicity occurred in both treatments, though it was faster in DU exposed to light $\left(k=0.07\right.$ day $\left.^{-1}\right)$ as compared to DU under darkness $\left(k=0.05 \mathrm{day}^{-1}\right)$. Exposure of DU to a direct light source enhances decay of estrogenicity, however, losses of available $\mathrm{N}$ can be significant.

Conclusions While reduction of estrogenic activity in DU stored under dark conditions takes longer, it is easy and does not require expensive equipment, energy sources or profound chemical expertise. Therefore, we suggest storage of DU under dark conditions as the best option for small-scale farmers and households in rural areas of developing countries.
\end{abstract}

Keywords Human urine $\cdot$ Steroidal estrogens $\cdot$ Biodegradation $\cdot$ Photodegradation $\cdot$ YES assay

\section{Introduction}

Use of human urine as a fertilizer is an ancient practice that lately has gained more interest, especially in developing and transition countries. The reason is that human urine contains an important amount of nutrients readily available for plants that make it efficient compared to other manures and commercial mineral fertilizers (Karak and Bhattacharyya 2011). In addition, recycling of urine reduces fertilizer cost investment and pollution effects from unsafe excreta disposal plus costly wastewater treatments.

Despite the benefits, reutilization of human excreta in agriculture has been associated with health and

Maria Alejandra Arias

marialejandrarias@gmail.com

1 Department of Plant Nutrition, University of Bonn - Institute of Crop Science and Resource Conservation (INRES), Karlrobert-Kreiten Straße 13, 53115 Bonn, Germany environmental risks and socio-cultural issues (WHO 2006). Urine is a waste product that comprises the metabolites and noxious substances the human body has to dispose of. Therefore, a range of pollutants, such as residues of pharmaceutical compounds and natural and synthetic hormones can be found (Lienert et al. 2007). It has been suggested that micropollutants could accumulate in soils and might be taken up by plants through the use of untreated urine as fertilizer and thus enter the food chains (Winker 2009).

Accumulation of natural and synthetic estrogenic compounds in the environment has received considerable attention as explained by the studies of Desbrow et al. (1998) and Routledge et al. (1998) who identified the major estrogenic chemicals present in sewage treatment works' effluents that received mainly domestic wastewater and were discharged into British rivers. The authors evidenced that those steroidal estrogens in sewage effluents induce the synthesis of vitellogenin in male fish placed downstream of effluent discharges. Other effects of estrogenic compounds on wild 
organisms are summarized in Hamid and Eskicioglu (2012). In humans, consumption of estrogens above the safe threshold has been associated with increase in the risk of cancer and cardiovascular diseases (Wocławek-Potocka et al. 2013; Moore et al. 2016).

Although human urine contains many natural estrogens, steroidal estrogens estrone (E1), 17 $\beta$-estradiol (E2) and estriol (E3) and their respective conjugates are the most abundant. It has been reported that premenopausal women can excrete an average rate of 7.3-13.8 $\mu \mathrm{g} \mathrm{day}^{-1}$ of E1, 2.8-3.6 $\mu \mathrm{g} \mathrm{day}^{-1}$ of E2 and 4.5-13.6 $\mu \mathrm{g} \mathrm{day}^{-1}$ of E3, while men can excrete rates up to $4 \mu \mathrm{g} \mathrm{day}^{-1} \mathrm{E} 1,1.5 \mu \mathrm{g}$ day $^{-1}$ E2 and $1.5 \mu$ day $^{-1}$ E3 (Liu et al. 2009). Together with the synthetic estrogen $17 \alpha$-ethinylestradiol (EE2), steroidal estrogens E1, E2 and E3 are most common in wastewater and apparently the main endocrine disruptors in the environment (Khanal et al. 2006). Because of the need for finding efficient methods for the removal of estrogens from contaminated waters, different strategies have been studied. Among other options, biological processes and exposure to ultraviolet radiation or the so-called photolysis are the most common (Silva et al. 2012).

As there is a risk of spreading estrogenic compounds onto the farming fields by human urine application as fertilizer, it is important to understand the turnover of estrogens during its storage and hopefully reduce its activity. The present study thus aims at evaluating the potential decay of naturally excreted estrogens in diluted urine (urine + flushed water) under simulated light and dark conditions and to elucidate the influence of intrinsic parameters of diluted human urine (e.g., dissolved organic carbon, ammonium, $\mathrm{pH}$, and electric conductivity) on the decline process. We thus hypothesize that estrogenicity in human urine can be reduced by irradiation as well as by microbial activity in the dark.

\section{Materials and methods}

\section{Source-separated diluted urine}

Diluted urine was collected from a private household, where a Gustavsberg Separation Toilet (Berger Biotechnik ${ }^{\circledR}$ $\mathrm{GmbH}$ ) has been installed. This toilet divides the urine from solid waste flush by an ergonomically adapted adjustment of the drains in the toilet bowl. As many people use toilet paper after urinating, the Gustavsberg Separation Toilet flushes both sewers each time. Flushing water volume is $2 \mathrm{~L}$ and $4 \mathrm{~L}$ for urine and solid waste, respectively; $10 \%$ of each flushing is used to empty the urine siphon. This way, the sediments of urine scale and blockage of the sewage pipes can be avoided. The urine obtained is diluted approximately by a factor of $1: 8$. For this reason, we refer to this fraction as diluted urine (DU).
For this study, the donors were a two-member family, a male and female couple, with no intake of pharmaceuticals or additional estrogens. Further characteristics of the DU used in this study are shown in Table 1. For the purpose of this experiment, DU was collected after 2 weeks of being excreted in a daily basis. DU urine was first thoroughly mixed inside the collection tank. Afterwards, $20 \mathrm{~L}$ of DU was collected in a $25 \mathrm{~L}$ container. DU was not spiked with any additional estrogens.

\section{Experimental setup}

The experiment was set up in an environmental chamber PERCIVAL E-36HO equipped with compact fluorescent lamps (55 W) and CLEO compact PLL lamps $(36 \mathrm{~W})$ covering the range of UV-B, UV-A and visible light $(280-700 \mathrm{~nm})$. The environmental chamber was programmed to run with $10 \mathrm{~h}$ of darkness and $14 \mathrm{~h}$ of light. Relative humidity $(\mathrm{RH}=60 \%)$ and air temperature $\left(23^{\circ} \mathrm{C}\right)$ were kept constant.

The experiment consisted of two treatments, both performed at the same time: (1) DU under dark conditions and (2) DU exposed to light. Each treatment had six repetitions. $300 \mathrm{~mL}$ of DU was used per repetition and stored in $300 \mathrm{~mL}$ Erlenmeyer soda lime glass flasks that allowed light transmittance throughout. To create dark conditions (treatment 1 ), flasks were completely wrapped with aluminum foil. Light-exposed flasks were only covered with crystal clear polystyrene lids, which allowed a light transmission of $90 \%$ of the 320-800 nm spectrum (BASF 2010). Before starting the experiment, all the glasswares were thoroughly washed, cleaned twice with absolute ethanol and kept in the oven at $180{ }^{\circ} \mathrm{C}$ for $4 \mathrm{~h}$ for surface sterilization. The same process was followed for cleaning the glass pipettes after sample collection. Samples were collected at day 0, 1, 2, 3, $5,7,9,12,15,20,40$, and 75 at a volume of $10 \mathrm{~mL}$ of DU two times from each of the six repetitions and transferred into glass vials. One of the $10 \mathrm{~mL}$ replicate of every repetition was used to measure $\mathrm{pH}$ and electrical conductivity

Table 1 Characteristics of diluted human urine used in the present study

\begin{tabular}{lc}
\hline Chemical parameters & Concentration \\
\hline$N_{\text {tot }}\left(\mathrm{g} \mathrm{L}^{-1}\right)$ & 1.86 \\
$\mathrm{NH}_{4}-\mathrm{N}\left(\mathrm{g} \mathrm{L}^{-1}\right)$ & 1.69 \\
$K\left(\mathrm{~g} \mathrm{~L}^{-1}\right)$ & 4.2 \\
Total P $\left(\mathrm{g} \mathrm{L}^{-1}\right)$ & 0.29 \\
$\mathrm{EC}\left(\mathrm{mS} \mathrm{cm}^{-1}\right)$ & 14.7 \\
$\mathrm{pH}$ & 9.2 \\
$\mathrm{E} 2 \mathrm{EQs}^{\mathrm{a}}\left(\mu \mathrm{g} \mathrm{L}^{-1}\right)$ & $2.41 \pm 0.7$ \\
\hline
\end{tabular}

${ }^{\mathrm{a}}$ Concentration of estrogenicity as equivalents of $17 \beta$-estradiol 
(EC) immediately after sample collection. The other replicates were kept at $-20{ }^{\circ} \mathrm{C}$ until analysis. By using separate samples, we avoided contamination through $\mathrm{pH}$ and $\mathrm{EC}$ electrodes.

\section{Chemicals}

Chlorophenol red- $\beta$-D-galactopyranoside (CPRG) and $17 \beta$-estradiol were purchased from Sigma-Aldrich Chemie (Germany). Methanol (99.9\% purity) HPLC Ultra Gradient Grade (UGG) ROTISOLV ${ }^{\circledR}$, acetone (99.9\% purity) HPLC UGG ROTISOLV $^{\circledR}$ and water HPLC UGG ROTISOLV ${ }^{\circledR}$ were purchased from ROTH (Germany). Ultrapure water was obtained from a Millipore Quantum ${ }^{\circledR}$ Ex purification system.

\section{Extraction of DU samples for analysis of estrogens}

Estrogens in DU were extracted by means of solid phase extraction (SPE) using Phenomenex Strata- $\mathrm{X}^{\circledR}$ polymeric sorbent reversed phase column $200 \mathrm{mg} / 6 \mathrm{~mL}$ (8B-S100FCH), connected to a Tall Boy ${ }^{\mathrm{TM}} 10$ position Vacuum manifold (Phenomenex). Glassware was previously washed with distilled water, rinsed twice with absolute ethanol and sterilized in the oven at $180{ }^{\circ} \mathrm{C}$ overnight. SPE columns were activated with $7 \mathrm{~mL}$ of methanol $100 \%$ and then washed with $7 \mathrm{~mL}$ of methanol $5 \%$. Thereafter, $8 \mathrm{~mL}$ DU was loaded onto the SPE column and drained with a flow rate of $5.5-6 \mathrm{~mL} \mathrm{~min}^{-1}$. Before the column ran dry, $7 \mathrm{~mL}$ of methanol $50 \%$ was loaded followed by $7 \mathrm{~mL}$ of acetone:water 1:2. SPE columns were dried under nitrogen gas (99.9\%) for at least $30 \mathrm{~min}$. Estrogens in DU were eluted from the dried columns by $7 \mathrm{~mL}$ of methanol $100 \%$ into sterilized glass vials and kept at $-20{ }^{\circ} \mathrm{C}$ until analysis.

\section{Analytical methods}

\section{Yeast estrogen screen (YES) assay}

Estrogenic activity was determined by the YES assay as described in detail by Routledge and Sumpter (1996). A recombinant yeast strain (Saccharomyces cerevisiae) containing the human estrogen receptor gene (hER) was obtained from Dr. Sumpter of Brunel University (Middlesex, UK). The strain also contains the expression plasmids carrying the reporter gene Lac-Z, encoding the enzyme $\beta$-galactosidase. When the cells are incubated in the presence of estrogenic compounds, the reporter gene Lac- $\mathrm{Z}$ produces $\beta$-galactosidase into the medium and causes the chromogenic substrate, chlorophenol red- $\beta$-D-galactopyranoside (CPRG) to turn red. This color change can be quantified by measuring the absorbance. In the present study, $100 \mu \mathrm{L}$ of an antibiotic mixture $(1 \mathrm{mg}$ penicillin and $1 \mathrm{mg}$ streptomycin in $20 \mathrm{~mL}$ sterilized ultrapure water) was added to $50 \mathrm{~mL}$ of assay medium to avoid bacterial contamination on the assay plates. The medium was seeded with $2 \mathrm{~mL}$ yeast from a $24 \mathrm{~h}$ culture which had reached an absorbance of $0.9-1.0$ at $630 \mathrm{~nm}$. A row of blanks (100\% UGG methanol) and a row of standards of $17 \beta$-estradiol (from 2 to $2700 \mathrm{ng} \mathrm{L}^{-1}$ ) were used in each plate. Aliquots of $10 \mu \mathrm{L}$ of blanks, each standard concentration and extracted samples were transferred to four wells of a sterilized 96-well optical flat bottom microtitre plate (Nunc, Germany). Methanol was allowed to evaporate to dryness and $200 \mu \mathrm{L}$ of the assay medium with CPRG $(0.5 \mathrm{~mL}$ of substrate solution in $50 \mathrm{~mL}$ of growth medium) was added using an 8-channel pipette. The chromogenic CPRG stock substrate solution was prepared by dissolving $10 \mathrm{mg}$ CPRG in $1 \mathrm{~mL}$ UGG water and sterilized by filtering through a $0.2 \mu \mathrm{m}$ pore size filter into a sterilized glass vial. Plates were incubated at $32{ }^{\circ} \mathrm{C}$ during 3 days. Every day, plates were shaken for $3 \mathrm{~min}$. After incubation, absorbance was read on a BIOTEK ELx $800^{\mathrm{TM}}$ microplate reader with the analysis software Gen5 ${ }^{\mathrm{TM}}$. The color development was measured at $540 \mathrm{~nm}$ and the turbidity of yeast cell biomass was read at $630 \mathrm{~nm}$. The measurement was corrected with the turbidity values according to Eq. 1:

$$
\begin{aligned}
& \text { Corrected value }=\text { Test }_{\text {absorbance }}{ }_{540 \mathrm{~nm}} \\
& -\left(\text { Test absorbance }_{630 \mathrm{~nm}}-\text { Blank absorbance }_{630 \mathrm{~nm}}\right)
\end{aligned}
$$

The calibration of the $17 \beta$-estradiol standard curve was performed with the four-parameter logistic model (4PL) (Findlay and Dillard 2007). Estrogenic activity is presented as a concentration of $17 \beta$-estradiol equivalents ( $\mu \mathrm{g} \mathrm{L}^{-1} \mathrm{E} 2 \mathrm{EQs}$ ).

The limit of detection (LOD) was calculated based on the volume of the sample used for extraction $(8 \mathrm{~mL})$, the volume of the eluted sample $(7 \mathrm{~mL})$ and the lowest concentration that can be detected in the assay plate ( $\left.20 \mathrm{ng} \mathrm{L}^{-1} \mathrm{E} 2 \mathrm{EQs}\right)$. In our case, the LOD for DU samples amounted to $0.02 \mu \mathrm{g} \mathrm{L}^{-1} \mathrm{E} 2$ EQs.

\section{Further chemical analyses}

The concentrations of total nitrogen $\left(\mathrm{N}_{\mathrm{tot}}\right)$, ammonium- $\mathrm{N}$ $\left(\mathrm{NH}_{4}-\mathrm{N}\right)$ and dissolved organic carbon (DOC) were measured by a continuous flow analyzer (AutoAnalyzer3 BRAN + LUEBBE Germany). Electrical conductivity (EC) and $\mathrm{pH}$ were determined by a $\mathrm{pH}$ SenTix 41 WTW electrode and the TetraCon ${ }^{\circledR} 325 \mathrm{EC}$ electrode run with a Multi 340i WTW set.

\section{Statistical analysis}

Changes in estrogenic activity in diluted urine under light and dark conditions were calculated based on the assumption that natural estrogens E1, E2 and E3 follow first-order 
kinetics (Chowdhury et al. 2011). The pseudo-first-order degradation rate constant was calculated from the slope of the logarithmic plot of estrogenic concentration as a function of time using, Eq. 2, and the half-life of estrogenicity was calculated by Eq. 3

$\ln \left(C_{\mathrm{E} 2 \mathrm{EQs}} / C_{0 \mathrm{E} 2 \mathrm{EQs}}\right)=-k t$

$t_{1 / 2}=\ln 2 / k$

where $C_{0 \mathrm{E} 2 \mathrm{EQs}}$ and $C_{\mathrm{E} 2 \mathrm{EQs}}$ are the concentrations of estrogens at time zero and thereafter, $k$ is the reaction rate $\left(\right.$ day $\left.^{-1}\right)$ and $t_{1 / 2}$ or half-life refers to the time in days needed to degrade $50 \%$ of the initial concentration.

Decay of estrogenic activity was calculated until day 20. Data corresponding to day 40 and 75 are not used in statistical analysis. Datasets were tested for homogeneity of variance (Levene median test) and normal distribution (Shapiro-Wilk test). Additionally, Pearson's moment correlation coefficient was obtained to understand the dependence between the variables evaluated. Statistical analysis was performed using SigmaPlot 11.0.

\section{Results and discussion}

\section{Estrogenic activity in DU under light and dark conditions}

In this study, a reduction in estrogenic activity after 20 days in both treatments, DU stored under light and dark conditions, was found. The average concentration of estrogenic activity in DU at day 0 was determined as $2.41 \pm 0.7 \mu \mathrm{g} \mathrm{L}^{-1}$ E2 EQs. The plot of $\ln \left(C_{\mathrm{E} 2 \mathrm{EQ}} / C_{0 \mathrm{E} 2 \mathrm{EQs}}\right)$ versus time (Fig. 1$)$ shows that the decay reaction rate $(k)$ of estrogenic activity until day 20 was faster in DU under light $\left(0.07 \mathrm{day}^{-1}\right)$ than in dark $\left(0.05 \mathrm{day}^{-1}\right)$. Additionally, the half-life $\left(t_{1 / 2}\right)$ was calculated as 10.05 and 12.60 days for DU under light and dark, respectively. After 20 days, $76 \%$ and $54 \%$ of initial estrogenic activity was reduced in DU under light and under dark, respectively.

According to data from DU under light corresponding to days 40 and 75, estrogenic activity was at zero level. However, concentration values of repetition samples at day 40 varied considerably resulting in very high standard deviation values. Likewise, values from day 75 were found to be much lower than the detection limit. Therefore, these data were not used in the statistical analysis to avoid erroneous conclusions. In the case of DU stored in dark conditions, data suggested an increase of $3.53 \pm 0.2 \mu \mathrm{g} \mathrm{L}^{-1} \mathrm{E} 2 \mathrm{EQs}$ in the estrogenic activity at day 40 , which was higher compared to the concentration found at day $0\left(2.41 \pm 0.7 \mu \mathrm{g} \mathrm{L}^{-1} \mathrm{E} 2\right.$ EQs). Though such an increase can occur, for the purpose

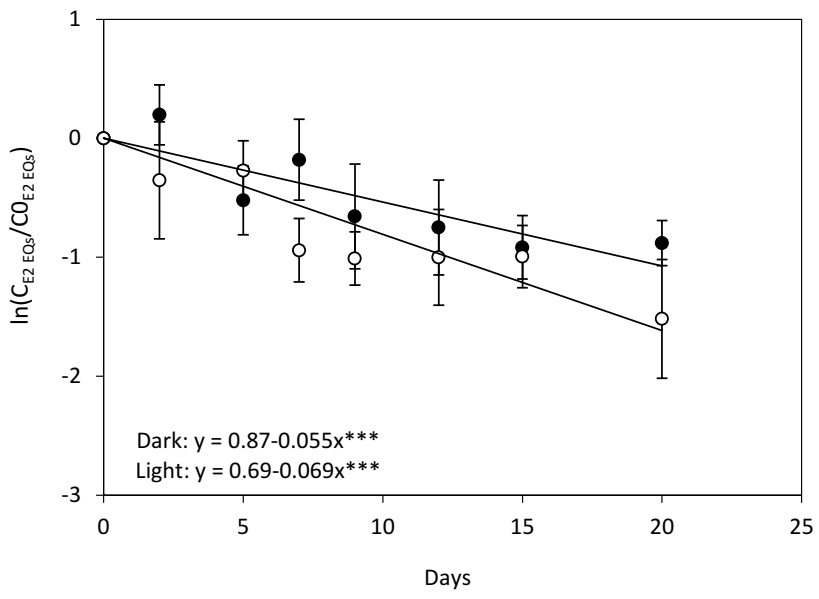

Fig. 1 Decay rate of estrogenic activity in DU under dark and light conditions over time. $N=4$. $* * * p<0.0001$. Filled circle represents urine under dark; open circle represents urine exposed to light. Dark $R^{2}=0.77$; Light $R^{2}=0.81$. Error bars represent the standard deviation of the mean

of statistical comparison of estrogenic activity between the two treatments only data until day 20 were used.

Increase in estrogenicity is most likely due to hydrolysis of conjugated estrogens. In both male and female urine, the majority of the excreted estrogens are conjugated and biologically less active, mostly through esterification by glucuronide and/or sulfate groups. The esterification is a biological mechanism used to detoxify free estrogens and render them more soluble and readily excreted (Khanal et al. 2006). As conjugated estrogens reach the sewer system, they can be split into free estrogens by microorganisms producing $\beta$-glucuronidases (e.g., E. coli) and/or arylsulfatases (Ternes et al. 1999; Khanal et al. 2006; Gomes et al. 2009). Therefore, as conjugated estrogens do not exhibit estrogenicity, hydrolysis of conjugated estrogens into free estrogens might result in an increase in total estrogenic activity. In a scenario of higher rates of estrogen excretion (e.g., excretion from pregnant women, women under hormonal contraception treatment) and higher amounts of urine collection, hydrolysis of estrogens may take longer, probably leading to a longer period for reduction of estrogenic activity. However, urine collected from a bigger group of individuals may lead to higher density and diversity of microorganisms which may also increase decay efficiency.

Another process that could explain the increase in estrogenic activity is the interconversion of $\mathrm{E} 1$ into $\mathrm{E} 2$, as has been demonstrated by Järvenpää et al. (1980). By an in vitro experiment, the authors found that the intestinal microorganisms Alcaligenes faecalis, Pseudomonas aeruginosa and Staphylococcus aureus were able to convert E2 into E1 and vice versa, while Mycobacterium smegmatis could only reduce E1 to E2. Since E2 has the highest estrogenic 
potency compared to E1 (E2 = 1 E2 EQs; E1 =0.1-0.2 E2 EQs) (Khanal et al. 2006), the accumulation of E2 over time would result in an increase of estrogenic activity.

In this study, the YES assay was used to detect the total estrogenic potency in DU during the experimental period, independent of the type of compounds in the sample (parent or intermediate degradation products). As we could not assess whether the aforementioned microorganisms were present in DU nor follow individual reactions, specific analytical methods have to be applied to follow the fate of individual estrogenic compounds under our experimental conditions.

\section{Degradation of estrogens under light and dark conditions}

Other studies have investigated the degradation of natural and synthetic estrogens under simulated and natural sunlight (see Table 2). However, to our knowledge, there is no study addressing the degradation of estrogens in diluted urine. Results shown in Table 2 suggest a more efficient photodegradation of estrogens in a water matrix as compared to the results in the present study. Yet our results may suggest that a longer storage period of DU under light would result in a total decay of estrogenic activity.

In this study, the decay of estrogenic activity in DU under dark was only moderately lower than in DU under light. Therefore, we suggest that the decay of estrogenic compounds under dark most likely originated by microorganisms. Biotic degradation has been suggested as one of the most effective ways for removal of estrogenic compounds in freshwater systems (Jürgens et al. 2002) and wastewater treatment plants (Yoshimoto et al. 2004). Although urine is sterile in the bladder, many different microorganisms may grow in the DU after excretion, and cross-contamination with fecal bacteria can occur (Schönning et al. 2002; Wohlsager et al. 2010), especially in the toilet system used to collect the urine for this study, with spillover from the feces flushing.
Efficiency and rate of degradation of estrogenic compounds may depend on the diversity and density of microorganisms. In the present experiment with DU, the load of microorganisms was most probably lower as compared to a wastewater treatment plant, and thus the reactions may have slowed down. Furthermore, the densities of microbial populations could have also been affected by DU conditions (such as increased $\mathrm{pH}$ and ammonium concentrations) as reported by Schönning et al. (2002) and Wohlsager et al. (2010). Nevertheless, some enteric and opportunistic pathogens as E. coli can have a longer survival time in DU at a ratio of 1:9 than in undiluted urine (Höglund 2001), which is close to the dilution ration used in this study (1:8).

\section{Dissolved organic carbon (DOC)}

The average content of DOC in DU at day 0 was found to be as high as $986 \mathrm{mg} \mathrm{L}^{-1}$. Along the experimental period, DOC decayed exponentially following the first-order kinetics model (Fig. 2). The reaction rate $(k)$ indicated that DOC decay was higher in DU under dark $\left(0.03\right.$ day $\left.^{-1}\right)$ than in DU exposed to light $\left(0.02 \mathrm{day}^{-1}\right)$. In both treatments, around $60 \%$ of the DOC decayed before day 20. However, in DU under light, the degradation process slowed down between day 20 and day 75, while it seemed to continue in DU under dark conditions. Thus, DOC losses were $85 \%$ under dark and $72 \%$ under light conditions. Within 20 days of incubation, estrogenic activity was significantly positively correlated to DOC in DU in dark $(r=0.721 ; p<0.001 ; N=32)$ and light $(r=0.689 ; p<0.001 ; N=32)$.

The fraction of dissolved organic matter (DOC) has been suggested to enhance the photodegradation of different pollutants in a water matrix (e.g., Canonica et al. 1995) as well as of steroidal estrogens, acting as a photosensitizer (Leech et al. 2009; Chowdhury et al. 2011). Yet, a high concentration of DOC can also hinder the degradation. Leech et al. (2009) found that a content of DOC higher than $15 \mathrm{mg} \mathrm{L}^{-1}$ saturates the solution and reduces the photodegradation of E2, by blocking the light transmittance, and thus the chance of photons to interact with the organic compounds. In this study, DOC was found to be in high concentrations (close to

Table 2 Results obtained in this study and previous studies evaluating photodegradation of natural and synthetic estrogens

\begin{tabular}{llllll}
\hline Estrogen & Initial conc. & Matrix & Light spectrum & $t_{1 / 2}$ & References \\
\hline Natural estrogens & $2.41 \mu \mathrm{g} \mathrm{L}^{-1}$ & Diluted urine & $280-700 \mathrm{~nm}$ & 10.05 day & This study \\
E1 & $100 \mu \mathrm{M}$ & Water & $290-700 \mathrm{~nm}$ & $7.9 \mathrm{~h}$ & Caupos et al. (2011) \\
& & Water +fulvic acid & & $5.3-7 \mathrm{~h}$ & \\
E2 & $5 \mu \mathrm{g} \mathrm{L}^{-1}$ & Water & $290-700 \mathrm{~nm}$ & $10.63 \mathrm{~h}$ & Chowdhury et al. (2011) \\
E1 & $100 \mathrm{mg} \mathrm{L}^{-1}$ & Water & Direct solar radiation & 55 days & Fonseca et al. (2011) \\
E2 & & & 60 days & \\
E3 & & & 40 days & \\
EE2 & & & $290-720 \mathrm{~nm}$ days & Leech et al. (2009) \\
E2 & $270 \mu \mathrm{g} \mathrm{L}^{-1}$ & Water & & $13.6 \mathrm{~h}$ &
\end{tabular}




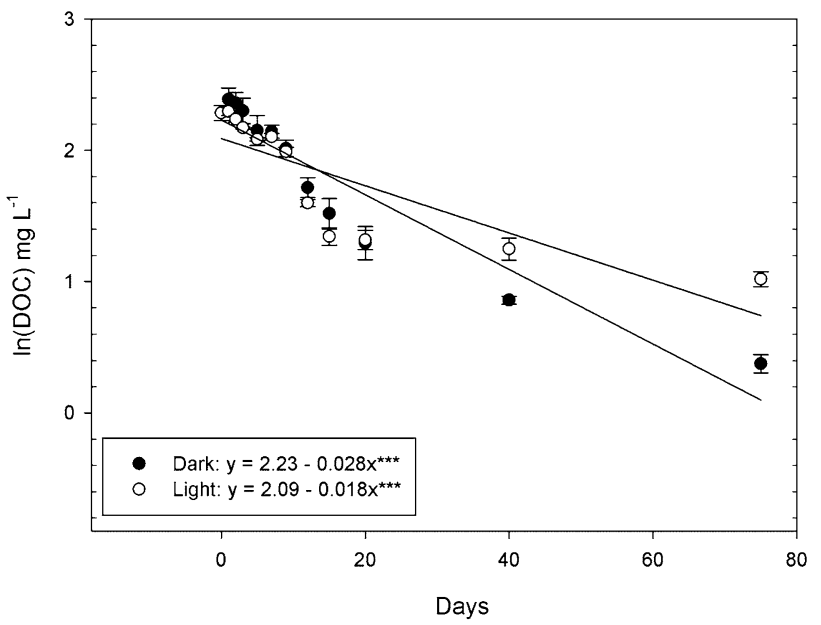

Fig. 2 Decay rate of DOC in DU under dark and light conditions. $N=4$. $* * *<0.0001$. Filled circle represents urine under dark; open circle represents urine exposed to light. Error bars represent the standard deviation of the mean

$1 \mathrm{~g} \mathrm{~L}^{-1}$ ) at the beginning of the experiment. This suggests that during the first few days of our experimental period, direct photolysis of estrogenic compounds was limited due to the elevated DOC content in DU. Over time, DOC degraded exponentially in both treatments and a correlation between the decline of both estrogenic potency and DOC was found. The reduction of DOC can be a result of light incidence of microorganism activity to obtain carbon as an energy source and loss of $\mathrm{CO}_{2}$. In several studies on natural water, natural light has been proven to break down dissolved organic matter into smaller molecules (e.g., Wetzel et al. 1995). In this study, it was observed that DU became clearer after day 15 , due to precipitation of organic matter, phosphates from urine and metal ions from both urine and flushing water (Höglund et al. 2000). The reduction of turbidity facilitated the transmittance of light in DU and thus the interaction of photons and estrogen molecules. Therefore, estrogens in DU exposed to light could undergo direct photolysis when DOC was depleted. Since reliable values of estrogenic activity could not be obtained after day 20 , future experiments should focus on longer-term degradation processes.

\section{Total nitrogen $\left(\mathrm{N}_{\text {tot }}\right)$ and ammonium-N $\left(\mathrm{NH}_{4}-\mathrm{N}\right)$}

Changes in $N_{\text {tot }}$ and $\mathrm{NH}_{4}-\mathrm{N}$ concentrations during the experimental phase are shown in Fig. 3. Initial $N_{\text {tot }}$ concentration was $1.86 \mathrm{~g} \mathrm{~L}^{-1}$, while $\mathrm{NH}_{4}-\mathrm{N}$ was $1.69 \mathrm{~g} \mathrm{~L}^{-1}$. This suggests that already at day 0 , almost $90 \%$ of the total nitrogen of DU was found as ammonium. Depletion of $N_{\text {tot }}$ and $\mathrm{NH}_{4}-\mathrm{N}$ occurred in both treatments. After 75 days, $71 \%$ and $82 \%$ of the $N_{\text {tot }}$ initial concentration were lost in dark and light, respectively. $\mathrm{NH}_{4}-\mathrm{N}$ decreased by $65 \%$ and $81 \%$ in dark and light, respectively.

Estrogenic activity showed a significant positive correlation to both $N_{\text {tot }}(r=0.399 ; p<0.05 ; N=32)$ and $\mathrm{NH}_{4}-\mathrm{N}$ $(r=0.357 ; p<0.05 ; N=32)$ in DU under dark. The same trend was found in DU under light for both $N_{\text {tot }}(r=0.523$; $p<0.05 ; N=32)$ and $\mathrm{NH}_{4}-\mathrm{N}(r=0.418 ; p<0.05 ; N=32)$. However, this result might be an external influence rather than an interaction of both parameters. Urea hydrolysis $\left[\mathrm{NH}_{2}(\mathrm{CO}) \mathrm{NH}_{2}+2 \mathrm{H}_{2} \mathrm{O} \rightarrow \mathrm{NH}_{3}+\mathrm{NH}_{4}{ }^{+}+\mathrm{HCO}_{3}{ }^{-}\right]$results in ammonia and bicarbonate accompanied by an increase in $\mathrm{pH}$. Due to the high $\mathrm{pH}$, up to one-third of the total ammonia consists of volatile ammonia (Udert 2002). Most likely, the ammonium/ammonia levels were lost over time ( $65 \%)$, due to dissipation through the clear polystyrene lids which could not be tight to avoid dissipation. Wohlsager et al. (2010) explained that DU stored open resulted in a $90 \% \mathrm{~N}$ loss while in closed storage, $93 \%$ of $\mathrm{N}$ was retained.
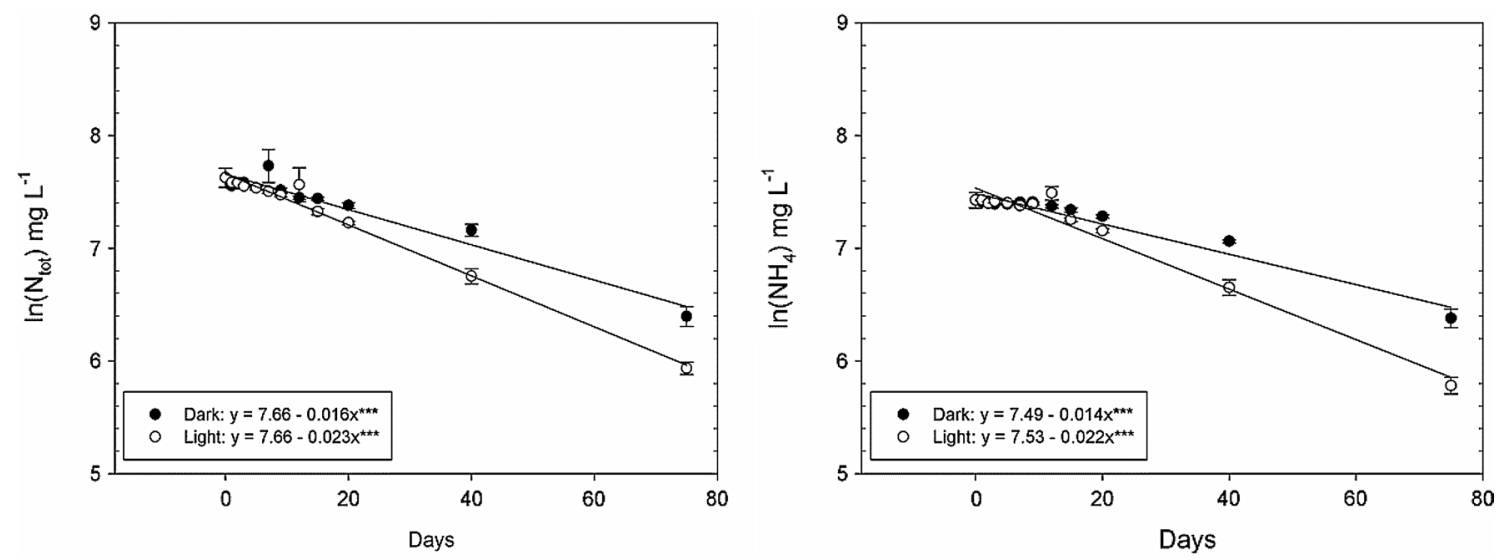

Fig. 3 Decay of $N_{\text {tot }}$ (left) and $\mathrm{NH}_{4}-\mathrm{N}$ (right) in DU under dark and light conditions over time. $N=4$. *** $p<0.0001$. Filled circle represents urine under dark; open circle represents urine exposed to light. Error bars represent the standard deviation of the mean 


\section{pH and electrical conductivity (EC)}

The measured initial value of $\mathrm{pH}$ in DU was 9.2, which is characteristic of DU that has undergone urea hydrolysis into ammonia, hydrogen carbonate and formation of $\mathrm{OH}^{-}$ions. Previous studies suggested that $\mathrm{pH}$ values of 7-8 can enhance the direct photolysis of E2 (Chowdhury et al. 2011) and the synthetic estrogen EE2 (Liu et al. 2003). In this study, the $\mathrm{pH}$ remained relatively constant during the experimental period in both treatments, reaching values of 9.7 and 9.5 in DU under dark and light conditions, respectively. No correlation to the decay of estrogenic activity in any of the treatments was found (data not shown).

Regarding EC, the initial value measured in DU was at $14.7 \mathrm{mS} \mathrm{cm}^{-1}$ and decreased during the time to $8.8 \mathrm{mS} \mathrm{cm}^{-1}$ in DU under dark and $8.1 \mathrm{mS} \mathrm{cm}^{-1}$ in DU exposed to light. This results from formation of particles and sedimentation. Höglund et al. (2000) found a higher concentration of phosphate, calcium and magnesium in the bottom sediments of urine storage tanks, in form of metal phosphates and metal hydroxides.

\section{Future trend and prospective of direct use of human urine as a fertilizer}

This study is part of an investigation addressing the potential risks of loading hormones and pharmaceutical micropollutants to field crops through the direct application of human urine as a source of nutrients. Human urine is a resource with high potential especially in low-income developing countries where smallholders face poor yields due to low levels of soil fertility and limited access to commercial mineral fertilizers. Therefore, local administrations should improve regulations regarding reuse of animal and human manures and encourage the safe use of these resources especially of human urine. The concerns regarding potential uptake of pharmaceuticals by plant crops and transfer to humans and animals should not pose a barrier for the use of human urine. On the contrary, this should encourage future studies. Nevertheless, use of human urine to fertilize smallholders' crops is harmless, because it is easier to know what is consumed by the (family) group and therefore what is excreted in the urine. Fertilization of fruit trees is also safe, because the chance of accumulation of micropollutants in the edible part (fruit or nut) is very low. A clever alternative to use human urine is the fertilization of crops that are not for human or animal consumption (e.g., energy plants, ornamental plants), and public gardens.

Another significant aspect to address for the better use of human excreta as fertilizer is the social perception. People need to transform the misconception of excreta as waste and dirt to view it as a resource. Therefore, more efforts should be made for institutions and community capacity building regarding ecological sanitation and reuse of excreta. This would encourage the implementation of projects, and the involvement and strong participation of communities for the sustainability of the projects.

\section{Conclusions}

This study showed that degradation of estrogenic compounds in DU occurs under both dark and light conditions. Estrogens decayed slightly faster in DU by exposure to sunlight. Yet, open storage where sunlight could hit directly the surface of the DU is not recommended due to the high loss of ammonium. Although stored DU in dark may require a longer period for the elimination of estrogenic activity, it is an easy, efficient and inexpensive method for safer urine reuse as fertilizer, suitable for smallholders and family gardens in developing and in-transition countries mainly for self-sufficient production. After application of DU onto the field, degradation of natural estrogens will occur due to direct sunlight exposure and higher diversity and density of microorganisms in the soil environment. Therefore, application of diluted human urine should not pose a problem. However, higher rates of application could result in slower capacity of degradation.

In practice, with continuous load of urine into the tanks, hydrolysis of conjugated estrogens is occurring constantly. Therefore, estrogenic activity may not be reduced until urine collection is stopped. Considering the $t_{1 / 2}$ times of estrogens, the storage time of $\sim 6$ months proposed by previous studies (e.g., Höglund 2001) may be sufficient not only for the reduction of pathogens but for estrogenic activity as well. Future studies should be directed to understanding the equilibrium rate of hydrolysis of conjugated estrogens versus degradation of estrogens. Also, it would be important to complement the YES assay with a specific analysis of free and conjugated estrogenic compounds to get a full assessment of their fate during storage and after application onto the field. Only following the free estrogens might lead to misinterpretations as long as not both conjugated and free estrogenic activities are only assessed.

Acknowledgements We thank the IPSWaT (International Postgraduate Studies in Water Technologies) program of the International Bureau of the German Federal Ministry of Education and Research, for funding the $\mathrm{PhD}$ studies of M.A. Arias.

Open Access This article is distributed under the terms of the Creative Commons Attribution 4.0 International License (http://creativeco mmons.org/licenses/by/4.0/), which permits unrestricted use, distribution, and reproduction in any medium, provided you give appropriate credit to the original author(s) and the source, provide a link to the Creative Commons license, and indicate if changes were made. 


\section{References}

BASF (2010) Polystyrene and Styrolux ${ }^{\circledR}$. http://zeus.phys.uconn.edu/ wiki/images/Polystyrene_properties.pdf. Accessed Oct 2015

Canonica S, Jans U, Stemmler K, Hoigne J (1995) Transformation kinetics of phenols in water: photosensitization by dissolved natural organic material and aromatic ketones. Environ Sci Technol 29:1822-1831. https://doi.org/10.1021/es00007a020

Caupos E, Mazellier P, Croue JP (2011) Photodegradation of estrone enhanced by dissolved organic matter under simulated sunlight. Water Res 45:3341-3350. https://doi.org/10.1016/j.watre s.2011.03.047

Chowdhury RR, Charpentier PA, Ray MB (2011) Photodegradation of $17 \beta$-estradiol in aquatic solution under solar irradiation: kinetics and influencing water parameters. J Photochem Photobiol A Chem 219:67-75. https://doi.org/10.1016/j.jphotochem.2011.01.019

Desbrow C, Routledge EJ, Brighty GC, Sumpter JP, Waldock M (1998) Identification of estrogenic chemicals in STW effluent. 1. Chemical fractionation and in vitro biological screening. Environ Sci Technol 32:1549-1558. https://doi.org/10.1021/es9707973

Findlay JWA, Dillard RF (2007) Appropriate calibration curve fitting in ligand binding assays. AAPS J 9:E260-E267. https://doi. org/10.1208/aapsj0902029

Fonseca AP, Lima DL, Esteves VI (2011) Degradation by solar radiation of estrogenic hormones monitored by UV-visible spectroscopy and capillary electrophoresis. Water Air Soil Pollut 215:441-447. https://doi.org/10.1007/s11270-010-0489-7

Gomes RL, Scrimshaw MD, Lester JN (2009) Fate of conjugated natural and synthetic steroid estrogens in crude sewage and activated sludge batch studies. Environ Sci Technol 43:3612-3618. https:// doi.org/10.1021/es801952h

Hamid H, Eskicioglu C (2012) Fate of estrogenic hormones in wastewater and sludge treatment: a review of properties and analytical detection techniques in sludge matrix. Water Res 46:5813-5833. https://doi.org/10.1016/j.watres.2012.08.002

Höglund C (2001) Evaluation of microbial health risks associated with the reuse of source-separated human urine. Dissertation, Royal Institute of Technology (KTH), Sweden

Höglund C, Vinnerås B, Stenström TA, Jönsson H (2000) Variation of chemical and microbial parameters in collection and storage tanks for source separated human urine. J Environ Sci Health Pt A 35:1463-1475. https://doi.org/10.1080/10934520009377047

Järvenpää P, Kosunen T, Fotsis T, Adlercreutz H (1980) In vitro metabolism of estrogens by isolated intestinal micro-organisms and by human faecal microflora. J Steroid Biochem 13:345-349. https:// doi.org/10.1016/0022-4731(80)90014-X

Jürgens MD, Holthaus KIE, Johnson AC, Smith JJL, Hetheridge M, Williams RJ (2002) The potential for estradiol and ethinylestradiol degradation in English rivers. Environ Toxicol Chem 21:480-488. https://doi.org/10.1002/etc.5620210302

Karak T, Bhattacharyya P (2011) Human urine as a source of alternative natural fertilizer in agriculture: a flight of fancy or an achievable reality. Resour Conserv Recycl 55:400-408. https://doi. org/10.1016/j.resconrec.2010.12.008

Khanal SK, Xie B, Thompson ML, Sung S, Ong S-K, van Leeuwen J (2006) Fate, transport, and biodegradation of natural estrogens in the environment and engineered systems. Environ Sci Technol 40:6537-6546. https://doi.org/10.1021/es0607739

Leech DM, Snyder MT, Wetzel RG (2009) Natural organic matter and sunlight accelerate the degradation of $17 ß$-estradiol in water. Sci Total Environ 407:2087-2092. https://doi.org/10.1016/j.scito tenv.2008.11.018

Lienert J, Bürki T, Escher BI (2007) Reducing micropollutants with source control: substance flow analysis of 212 pharmaceuticals in faeces and urine. Water Sci Technol 56:87-96. https://doi. org/10.2166/wst.2007.560
Liu B, Wu F, Deng NS (2003) UV-light induced photodegradation of $17 \alpha$-ethynylestradiol in aqueous solutions. J Hazard Mater 98:311-316. https://doi.org/10.1016/S0304-3894(02)00321-7

Liu ZH, Kanjo Y, Mizutani S (2009) Urinary excretion rates of natural estrogens and androgens from humans, and their occurrence and fate in the environment: a review. Sci Total Environ 407:49754985. https://doi.org/10.1016/j.scitotenv.2009.06.001

Moore SC, Matthews CE, Ou Shu X, Yu K, Gail MH, Xu X, Ji BT, Chow WH, Cai Q, Li H, Yang G, Ruggieri D, Boyd-Morin J, Rothman N, Hoover RN, Gao YT, Zheng W, Ziegler RG (2016) Endogenous estrogens, estrogen metabolites, and breast cancer risk in postmenopausal chinese women. J Natl Cancer Inst 108:103. https://doi.org/10.1093/jnci/djw103

Routledge EJ, Sumpter JP (1996) Estrogenic activity of surfactants and some of their degradation products assessed using a recombinant yeast screen. Environ Toxicol Chem 15:241-248. https:// doi.org/10.1002/etc.5620150303

Routledge EJ, Sheahan D, Desbrow C, Brighty GC, Waldock M, Sumpter JP (1998) Identification of estrogenic chemicals in STW effluent. 2. In Vivo responses in trout and roach. Environ Sci Technol 32:1559-1565. https://doi.org/10.1021/es970796a

Schönning C, Leeming R, Stenström TA (2002) Faecal contamination of source-separated human urine based on the content of faecal sterols. Water Res 36:1965-1972. https://doi.org/10.1016/S0043 -1354(01)00427-4

Silva CP, Otero M, Esteves V (2012) Processes for the elimination of estrogenic steroid hormones from water: a review. Environ Pollut 165:38-58. https://doi.org/10.1016/j.envpol.2012.02.002

Ternes TA, Kreckel P, Mueller J (1999) Behaviour and occurrence of estrogens in municipal sewage treatment plants-II. Aerobic batch experiments with activated sludge. Sci Total Environ 225:91-99. https://doi.org/10.1016/S0048-9697(98)00335-0

Udert KM (2002) The fate of nitrogen and phosphorus in source-separated urine. Dissertation, Swiss Federal Institute of Technology Zurich, Switzerland

Wetzel RG, Hatcher PG, Bianchi TS (1995) Natural photolysis by ultraviolet irradiance of recalcitrant dissolved organic matter to simple substrates for rapid bacterial metabolism. Limnol Oceanogr 40:1369-1380. https://doi.org/10.4319/lo.1995.40.8.1369

WHO (2006) Guidelines for the safe use of wastewater, excreta and greywater. Volume IV: excreta and greywater use in agriculture, vol 1. World Health Organization, Switzerland

Winker M (2009) Pharmaceutical residues in urine and potential risks related to usage as fertiliser in agriculture. Dissertation, Hamburg University of Technology, Germany

Wocławek-Potocka I, Mannelli C, Boruszewska D, Kowalczyk-Zieba I, Waśniewski T, Skarżyński DJ (2013) Diverse effects of phytoestrogens on the reproductive performance: cow as a model. Int J Endocrinol 2013:15. https://doi.org/10.1155/2013/650984

Wohlsager S, Clemens J, Nguyet PT, Rechenburg A, Arnold U (2010) Urine-a valuable fertilizer with low risk after storage in the tropics. Water Environ Res 82:840-847. https://doi.org/10.2175/10614 3010X12609736967125

Yoshimoto T, Nagai F, Fujimoto J, Watanabe K, Mizukoshi H, Makino T, Kimura K, Saino H, Sawada H, Omura H (2004) Degradation of estrogens by Rhodococcus zopfii and Rhodococcus equi isolates from activated sludge in wastewater treatment plants. Appl Environ Microbiol 70:5283-5289. https://doi.org/10.1128/ aem.70.9.5283-5289.2004

Publisher's Note Springer Nature remains neutral with regard to jurisdictional claims in published maps and institutional affiliations. 